Copyright (C) 2017 by Academic Publishing House Researcher

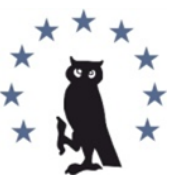

Published in the Russian Federation

European Researcher. Series A

Has been issued since 2010.

ISSN 2219-8229

E-ISSN 2224-0136

2017, 8(3): 201-211

DOI: $10.13187 /$ er.2017.3.201

www.erjournal.ru

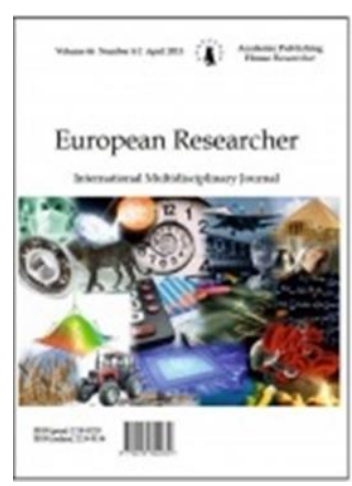

UDC 37

\title{
The Modern Models of Psychological and Pedagogical Support of Gifted Children
}

Nataliya I. Neskoromnykh a ,*

a Creativity and Humanitarian Education Center in Sochi, Municipal Educational Budgetary Institution of Further Education for Children, Russian Federation

\section{Abstract}

The article presents the research results on the modeling and design of professional activities in support of gifted children. The material for the analysis were scientific works, which describe both the results of modeling functioning psychological and pedagogical objects, and the existing (proposed) models of the process of psychological and pedagogical support of gifted children. Based on the system analysis and comparative approach, there is considered the composition, structure (methodological, target, content, structural, technological, management components), hierarchy of model components, and key design problems of each of them. It is shown that the psychological and pedagogical support of gifted children in educational organizations, built on the basis of theoretical models, is not without serious shortcomings. The ways of overcoming the revealed model errors are suggested.

The analysis of theoretical models of the process of psychological and pedagogical support of gifted children will make it possible to simulate this process at a better level and avoid the significant errors in modeling.

Keywords: gifted children, psychological and pedagogical support of gifted children, modeling, model of psychological and pedagogical support of gifted children.

\section{1. Введение}

Раннее выявление, развитие, поддержка одаренных и талантливых детей в комплексе составляют одну из приоритетных задач совершенствования современного российского образования, от решения которой зависит сохранение и преумножение интеллектуального и экономического потенциала страны. Эта задача закреплена во многих документах федерального, регионального и муниципального уровней.

В отечественной научной литературе и педагогической практике в последнее время уделяется большое внимание вопросам психолого-педагогического сопровождения детей с признаками одаренности. Признается, что такие дети могут иметь психологические трудности, проявляющиеся на когнитивном, эмоциональном и поведенческом уровнях, а особенности одаренной личности могут стать преградой, тормозящей проявление и развитие одаренности. Все это свидетельствует о необходимости создания особых психолого-педагогических условий, позволяющих усилить позитивное и нейтрализовать

\footnotetext{
${ }^{*}$ Corresponding author

E-mail addresses: nesknatali@mail.ru (N.I. Neskoromnykh)
} 
негативное влияние на интеллектуальное и творческое развитие детей с признаками одаренности, тем самым способствовать развитию личности с гармоничным типом одаренности.

Изучение современных моделей и моделирование процесса психологопедагогического сопровождения одаренных детей обусловлена, во-первых, необходимостью достижения новых целей образовательных организаций, связанных с совершенствованием системы выявления, сохранения и развития одаренности обучающихся; во-вторых, имеющимися недостатками построения сопровождения одаренных детей как на теоретическом, так и на практическом уровнях; в-третьих, необходимостью повышения качества психолого-педагогической работы по снижению и преодолению рисков возникновения проблемных ситуаций в развитии, обучении, социализации одаренных детей, «затухания» одаренности, формирования личности с дисгармоничным типом одаренности.

Теоретический анализ современных моделей процесса сопровождения одаренных детей (выбранных теоретических основ для моделирования, набора и иерархии структурных компонентов, связей между ними и др.) позволит на более качественном уровне обратиться к моделированию этого процесса и избежать существенных ошибок в моделировании.

\section{2. Материалы и методы}

Материалом исследования явилась научные и научно-методические публикации, в которых описаны модели или отдельные компоненты моделей процесса сопровождения одаренных детей.

Выбор инструментально-методического аппарата исследования обусловлен поставленной целью: получить общие представления о том, как функционирует система сопровождения одаренных детей в образовательных организациях в современных условиях; выявить наиболее слабые и сильные стороны такого сопровождения; определить основные направления модернизации сложившейся практики.

Использовались методы: систематизация и классификация материала, метод теоретического анализа и синтеза, сравнительно-сопоставительный метод, экспертный анализ, обобщение.

Реализация методов осуществлялась с опорой на следующие методологические основания: теории моделирования (С.И. Архангельский, Н.В. Бордовская, Ю.Н. Кулюткин, И.Б. Новик, А.М. Сохор, Ю.С. Тюнников, В.А. Штофф и др.); «Рабочую концепцию одаренности» (Д.Б. Богоявленская, В.Д. Шадриков, Ю.Д. Бабаева, А.В. Брушлинский, В.Н. Дружинин, И.И. Ильясов, И.В. Калиш, Н.С. Лейтес, А.М. Матюшкин, А.А. МеликПашаев, В.И. Панов, Д.В. Ушаков, М.А. Холодная, Н.Б. Шумакова, В.С. Юркевич) (Богоявленская и др., 2003); концепцию психологического здоровья детей (М.Р. Битянова, И.В. Дубровина, Р.В. Овчарова, В.И. Слободчиков, А.В. Шувалов и др.); экопсихологический и психодидактический подходы к обучению и развитию одаренных детей (В.А. Орлов, В.И. Панов); проектный подход в организации психолого-медико-социального сопровождения (Е.В. Бурмистрова, М.Р. Битянова, А.И. Красило и др.); теорию педагогической поддержки (Л.В. Байбородова, В.П. Бедерханова, О.С. Газман, Н.Б. Крылова, Н.Н. Михайлова, С.М. Юсфин и др.).

\section{3. Обсуждение}

Проблема детской одаренности и развития одаренности находится в поле зрения отечественных (Ю.Д. Бабаева, Д.Б. Богоявленская, Ю.З. Гильбух, В.Н. Дружинин, А.В.Золотарева, Н.С. Лейтес, А.М. Матюшкин, А.И. Савенков, М.А. Холодная, В.Д. Шадриков, В.С. Юркевич и др.) и зарубежных (Б. Блум, Дж. Гилфорт, М. Карне, Дж. Рензулли, К. Текекс, Ф. Уильямс и др.) исследователей. В России и за рубежом накоплен достаточно большой научно-методический арсенал теоретико-методологического обеспечения сопровождения одаренных детей. Изучены различные аспекты сопровождения развития и поддержки (Н.Р. Битянова, О.С. Газман, Е.И. Исаев, Н.Н. Михайлова, В.И. Слободчиков, Ю.В. Слюсарев, С.М. Юсфин и др.). Психолого-педагогическое сопровождение одаренных детей выделено в качестве необходимого условия развития их способностей (М.Н. Акимова, А.И. Доровской, Л.И. Ларионова, А.Н. Матюшкин, 
Н.В. Семенова, Н.Ю. Синягина, Е.Г. Чирковская и др.). Многие исследователи обращались к моделированию работы с одаренными детьми.

Моделирование как перспективный метод научного исследования широко применяется в педагогике, поскольку позволяет сочетать в ходе изучения педагогического объекта построение логических конструкций и научных абстракций с экспериментом. Практическая ценность модели в педагогическом исследовании определяется ее адекватностью изучаемым сторонам объекта и тем, насколько правильно учтены на этапах построения модели основные принципы моделирования (наглядности, определенности, объективности) (Михеев, 1987: 206).

Перспективные модели сопровождения одаренных детей характеризуются стремлением к интеграции различных концептуально-теоретических подходов и особым вниманием к вопросам организации психолого-педагогической практики. Вместе с тем современные модели сопровождения одаренных детей не лишены существенных недостатков, которые обусловлены не только сложностью, многофакторностью, изменчивостью самого объекта моделирования, но и просчетами и ошибками авторов моделей.

\section{4. Результаты}

Анализ теоретических моделей процесса психолого-педагогического сопровождения одаренных детей (Жалагина и др., 2014; Кошелева, 2013; Мельникова и др., 2015; Паненкова, 2014; Толстопятова, 2004) позволил сделать следующие важные для нашего исследования заключения:

1. В описании моделей процесса сопровождения одаренных детей нашли отражение концептуальные представления о психолого-педагогическом сопровождении на основе гуманистического, деятельностного, системного, комплексного, междисциплинарного и иных подходов.

2. Отечественными исследователями предложены различные модели сопровождения одаренных детей, большинство из которых построены на основе моделей М.Р. Битяновой, Е.И. Казаковой, Р.В. Овчаровой. Моделей процесса психолого-педагогического сопровождения одаренных детей в организации дополнительного образования сравнительно не много (О.А. Толстопятова; О.В. Мельникова, Л.В. Красавина, Е.В. Птачек и др.), ряд из них имеют узкую направленность (например, сопровождение младших школьников как субъектов образовательного процесса, социальной адаптации, на этапе подготовки к олимпиадам и др.), отдельные модели построены без обобщения передового опыта организации сопровождения одаренных детей, накопленного педагогической и психологической науками и практикой.

3. Модели психолого-педагогического сопровождения одаренных детей можно классифицировать в зависимости от особенностей объектов сопровождения:

- от проявленности детской одаренности - модели сопровождения детей с проявившейся (актуальной), нераскрывшейся (потенциальной) одаренностью;

- от проблем одаренных детей - модели сопровождения одаренных детей со школьной дезадаптацией, с ограниченными возможностями здоровья, с гармоничным, дисгармоничным типами развития одаренности и др.;

- от количества детей, составляющих объект сопровождения - модели системного сопровождения (направленного на профилактику или коррекцию проблем, характерных не для одного ребенка, а для системы в целом), индивидуального сопровождения (предполагающего создание условий для выявления потенциальной группы риска одаренных детей и гарантированную помощь им), комплексного сопровождения (предполагающего сочетание системного и индивидуального сопровождения).

4. Разработаны поли- или монофункциональные модели сопровождения одаренных детей. Среди функций моделей чаще всего представлены иллюстративная (позволяющая наглядно отобразить изучаемый процесс, его структуру) и объяснительная (способствующая формированию более ясного представления об объекте познания), гораздо реже эвристическая (направленная на открытие новых сторон исследуемого фрагмента социальной действительности), не встречаются - критериальная (направленная на осуществление сравнительного анализа и оценки отдельных свойств объекта), 
прогностическая (связанная с получением информации о дальнейшем функционировании и развитии исследуемого процесса).

5. Среди типичных ошибок авторов моделей процесса психолого-педагогического сопровождения одаренных детей выделяется несоблюдение требований к педагогической модели (см. требования к модели - (Новиков, Новиков, 2004: 37-38)):

- модель лишена ингерентности - не согласована в достаточной степени со средой, в которой ей предстоит функционировать, входить в эту среду как естественная составная часть (например, модель не соответствует особенностям организации дополнительного образования, на базе которой реализуется);

- модель не является простой - наряду с существенными качествами или характеристиками содержит менее важные и менее существенные (например, при описании модели авторы увеличивают степень детализации, моделью называют программу сопровождения);

- модель нельзя признать адекватной - нарушена целостность и логичность представления информации о целостной системе и ее функционировании (например, модель не соответствует теоретическим представлениям о детской одаренности), реализация модели не позволяет достичь всех поставленных целей и задач (цели не являются реалистичными).

Перечисленные погрешности моделей не позволяют им надлежаще функционировать, а построенное на их основе сопровождение детей не лишено серьезных недостатков.

Аспектный анализ моделей психолого-педагогического сопровождения одаренных детей проведен нами по пяти направлениям: 1) «функции и цели процесса психолого-педагогического сопровождения одаренных детей»; 2) «содержание процесса психолого-педагогического сопровождения одаренных детей»; 3) «структура процесса психолого-педагогического сопровождения одаренных детей»; 4) «инструментарий процесса психолого-педагогического сопровождения одаренных детей»; 5) «управление процессом сопровождения одаренных детей». Представим результаты анализа по каждому направлению.

Первое направление аспектного анализа («функции и цели процесса психолого-педагогического сопровождения одаренных детей») связано с изучением развернутой системы целей моделируемого процесса. В рамках такого анализа мы обратились к целевым характеристикам моделей процесса сопровождения, получили следующие результаты и заключения:

1. Цели процесса сопровождения соотносятся с так называемым «субъектным четырехугольником» (Казакова, 2001), включающим в себя ребенка, педагогов, родителей и ближайшее социальное окружение, а также специалиста взаимодействия, находящегося в центре и взаимодействующего с ними (с со-субъектами сопровождения). Авторы отдельных моделей раскрывают три основных поля развития для каждого из субъектов (со-субъектов) сопровождения: 1) помощь в выборе и проектировании (для ребенка - образовательной программы и образовательной организации, стратегий и моделей взаимодействия со сверстниками и взрослыми; для педагога - образовательной программы, образовательной технологии, стратегии взаимодействия с ребенком; для родителей - стратегии воспитания; для ближайшего социального окружения - стратегии взаимодействия с ребенком); 2) помощь в решении проблем детей в образовательном процессе (в преодолении затруднений); 3) помощь в преодолении проблем развития ребенка. Только в этом случае реализуется основное предназначение сопровождения - «системное проектирование развития, дающее основания для развития всех субъектов системы» (Казакова, 1998).

2. Выявлены целевые стратегии (ценностно-целевые ориентации) психологопедагогического сопровождения одаренных детей: стратегия выявления потенциальных возможностей, стратегия актуализации детской одаренности, стратегия развития детской одаренности, стратегия преодоления барьеров и нивелирования препятствий в развитии одаренности, стратегия поддержки высоких достижений одаренных детей, стратегия оказания помощи одаренным детям, стратегия предупреждения проблем и негативных явлений в развитии одаренных детей.

3. Чаще всего целевой компонент моделей не является многоуровневой иерархической структурой. Большинство разработчиков изученных нами моделей не обращаются к 
декомпозиции генеральной цели и не выстаивают «дерево» целей процесса сопровождения одаренных детей. Однако декомпозиция целей представляется весьма эффективной, поскольку содержание генеральной цели разворачивается в описание иерархической структуры подцелей, формулировка главной цели дает операциональное описание конечного результата, а корректная формулировка целей каждого уровня обеспечивает оценку их достижения.

4. Не редко цели сопровождения подменяются целями управления, помощи, развития (в формулировках целей не находит отражение центральная категория сопровождения «взаимодействие», «теряются» субъект-субъектные отношения).

5. В формулировках целей и задач выявлены следующие погрешности: размытость и множество общих слов, не относящихся к проблематике одаренности и содержанию сопровождения одаренных детей, некорректные формулировки.

В завершении анализа научных публикаций, диссертационных исследований, посвященных проблемам сопровождения одаренных детей, а также практики такого сопровождения обозначим ключевъе проблемъ в разработке целевого компонента моделей: 1) проблема адекватности системы целей процесса сопровождения одаренньх детей особенностям, трудностям и типичным проблемам этой категории детей; 2) проблема полноты целей процесса сопровождения одаренных детей («потеря» диагностических и/или консультативных, развивающих, коррекционных, профилактических и других важных целей); 3) проблема согласования целей между отдельньми звеньями (этапами) процесса сопровождения одаренных детей.

Для решения 1-й проблемы необходимо разработать целевой компонент модели с учетом особенностей одаренных детей и видом их одаренности. Для решения 2-й и 3-й проблем в практике педагогического проектирования применяется способ декомпозиции генеральной цели. Следовательно, необходимо в соответствии с определенными правилами построить «дерево» целей (В.П. Беспалько, Ю.С. Тюнников и др.) процесса психолого-педагогического сопровождения детей с признаками одаренности.

Второе направление аспектного анализа («содержание процесса психолого-педагогического сопровождения одареннъх детей») связано с изучением элементов содержания изучаемого процесса, обеспечивающих достижение поставленных целей. Мы изучили описание содержательных характеристик моделей процесса сопровождения одаренных детей и сделали следующие выводы:

1. Содержательный компонент моделей включает в себя основные, чаще всего согласованные между собой направления (виды работ) по сопровождению одаренных детей, реализуемые целостно. Приведем в качестве примера два наиболее типичных варианта:

1-й вариант: 1) профилактика; 2) диагностика (индивидуальная и групповая); 3) консультирование (индивидуальное и групповое); 4) развивающая работа (индивидуальная и групповая); 5) коррекционная работа (индивидуальная и групповая); 6) психологическое просвещение и образование: формирование психологической культуры, развитие психолого-педагогической компетентности учащихся, администрации образовательных учреждений, педагогов, родителей; 7) экспертиза (образовательных и учебных программ, проектов, пособий, образовательной среды, профессиональной деятельности специалистов образовательных учреждений) (Методические рекомендации...);

2-й вариант: 1) психодиагностическое (выявление одаренных детей); 2) психопрофилактическое, психокоррекционное, развивающее (создание психологопедагогических условий для адаптации и личностного развития одаренных детей); 3) учебновоспитательное (обучение и воспитание одаренных детей); 4) психолого-педагогическое консультирование и просвещение родителей и педагогов (Паненкова, 2014: 76).

2. Содержание психолого-педагогического сопровождения кроме этапов деятельности педагога-психолога (педагога) и ребенка включает управленческую деятельность образовательной организации, ориентированную на создание условий сопровождения.

3. Среди существенных недостатков содержательного компонента моделей процесса сопровождения одаренных детей выделим следующие: слабая согласованность цели и содержания сопровождения; построение содержания сопровождения без учета возрастных и гендерных особенностей детей; неоправданное дублирование одних локальных структур содержания другими; представленность не в полном объеме или отсутствие некоторых 
важных локальных структур содержания; не предусмотрены индивидуальные маршруты сопровождения; несогласованность между собой групповых и индивидуальных маршрутов сопровождения.

К ключевъм проблемам разработки содержательного компонента процесса психолого-педагогического сопровождения одаренных детей отнесены: 1) проблема адекватности содержания сопровождения его целям и задачам, содержанию и формам организации учебной и внеучебной деятельности детей; 2) проблема заполнения лакун 8 содержании многоэтапного процесса психолого-педагогического сопровождения одаренных детей (например, создание психологически безопасной образовательной среды сопровождения детской одаренности); 3) проблема недостаточного использования потенциала семьи и ближайшего социального окружения в решении проблем одаренного ребенка; 4) проблема объединения усилий всех субъектов психолого-педагогчческого сопровождения в единую систему.

Указанные проблемы в практике психолого-педагогического сопровождения детей с признаками одаренности могут быть решены за счет выделения приоритетов содержания процесса сопровождения, декомпозиции профессиональной деятельности по сопровождению и отдельных ее фрагментов, разработки всех необходимых операционнодеятельностных элементов содержания сопровождения, а также за счет теоретической разработки и применения сценарного подхода к моделированию содержания психологопедагогического сопровождения одаренных детей (в основу сценарного подхода могут быть положены теоретические заключения, предложенные Ю.С. Тюнниковым - (Тюнников, 2012а; Тюнников, 2012b)).

Третье направление аспектного анализа («структура процесса психолого-педагогического сопровождения одаренных детей») связано с изучением этапов этого процесса. На основе анализа структурно-логических характеристик моделей сделаны следующие заключения:

1. Психолого-педагогическое сопровождение одаренных детей в современном образовательном пространстве представляет собой хорошо структурированный вид деятельности. Модели психолого-педагогического сопровождения одаренных детей отличаются по количеству, названиям и наполняемости этапов сопровождения. Обобщив имеющиеся разработки, выделим 5 самостоятельных и взаимосвязанных этапов сопровождения:

1) диагностический (пропедевтико-диагностический, начальный, входной) выявление комплекса проблем, их оценка с точки зрения значимости для сопровождаемого);

2) аналитический (договорной, прогностический) - проведение сопровождающим совместно с сопровождаемым анализа сложившейся ситуации, поиск причин возникновения проблем и определение прогнозов успешности их разрешения;

3) проективный (проектировочный, поисково-вариативный, поисковый, этап планирования) - проектирование совместных действий сопровождаемого и сопровождающего по решению проблем;

4) реализации (деятельностный, практико-действенный) - реализация проекта по решению проблем (программы сопровождения);

5) рефлексивный (аналитико-рефлексивный, аналитико-прогностический, итоговый, заключительный) - повторная диагностика, обсуждение результатов предыдущих этапов сопровождения, рефлексия, осмысление сопровождаемым и сопровождающим нового опыта жизнедеятельности; прогнозирование возможности появления новых трудностей и проблем и путей их преодоления.

2. В описании структурного компонента многих моделей не показана цикличность процесса сопровождения, не дано обоснование этапов. Содержание процесса сопровождения отличается избыточностью либо имеет существенные пробелы. В структуре процесса сопровождения некоторых моделей отсутствуют этап (шаг) информационного поиска служб и специалистов, которые могут помочь решить проблемы, и этап (шаг) обсуждения возможных вариантов решения проблем со всеми заинтересованными специалистами и выбора наиболее целесообразного пути решения.

Обозначим ключевъц проблемъ в разработке структурного компонента моделей: 
1) проблема выделения необходимых и достаточных для достижения поставленной цели относительно самостоятельных и завершенных отрезков процесса сопровождения; 2) проблема описания этапов сопровождения как качественной определенности каждого последующего состояния процесса и как структуры компонентов.

Для решения этих проблем прибегают к обоснованию этапов сопровождения, логикоструктурной компоновке в реальном масштабе времени.

Четвертое направление аспектного анализа («инструментарий процесса психолого-педагогического сопровождения одареннъхх детей») предполагает изучение методов, технологий и средств, приводящих в движение содержание процесса сопровождения. На основе анализа инструментальных характеристик моделей психолого-педагогического сопровождения одаренных детей сделаны следующие выводы:

1. Авторы моделей предлагают разнообразные по функциям, содержанию, структуре технологии, формы и методы сопровождения. Традиционно в процессе сопровождения одаренных детей используется комплекс:

- технологий (арт-технологии, проектно-исследовательская, диалоговая, создания поддерживающей и развивающей среды, формирования мотивации на изменение поведения, портфолио, разрешения проблем, коррекционные и др.);

- методов: практико-действенньх (воспитывающие ситуации, упражнения, приучения, иллюстрации, игровые, моделирование поведения и др.), информационнопознавательных (рассказ, бесед, объяснение, проблемное изложение, наблюдение и др.); побудительно-оценочных (педагогические требования, стимулирование поведения и деятельности и др.), коррекционно-развивающих (психологический тренинг, психорегуляции, психокоррекционные, психологического воздействия и др.), организации взаимодействия (согласование позиций, обмен информацией, организация деятельности и др.), диагностических;

- основных форм: индивидуальных (индивидуальные консультации, индивидуальные практикумы для детей и родителей, носящие развивающую и коррекционную направленность, индивидуальные занятия и др.), групповых (психологические тренинги для детей, семинар-практикум для родителей, групповые консультации, конкурсы, олимпиады и другие предметные мероприятия состязательного характера и др.);

- весь спектр традиционных приемов и средств (ролевые игры, приемы консультирования, просвещения, коллективно-творческие дела, информирование, ситуационные игры, создание ситуаций успеха, эмоционально-нравственных переживаний и др.).

Подчеркивается необходимость применения интерактивных методов, способствующих формированию ребенка как субъекта деятельности.

2. Основой сопровождения признается интеграция психологических, педагогических, психолого-педагогических технологий. Из компоновки различных технологий выстраиваются индивидуальные маршруты сопровождения.

3. Авторы некоторых моделей предлагают для научного и методического обеспечения психолого-педагогического сопровождения специально разработанные ими комплексные технологии.

Вместе с тем, как показал анализ научных публикаций и непосредственное ознакомление с психолого-педагогической практикой, ключевъцм проблемами в разработке психолого-педагогического инструментария процесса сопровождения одаренных детей остаются: 1) разработка и согласование психолого-педагогического инструментария по всему спектру задач процесса сопровождения одаренных детей; 2) создание $u$ отбор психолого-педагогического инструментария, адекватного структуре и особенностям многоэтапного процесса сопровождения одаренных детей.

Указанные проблемы в практике сопровождения детей с признаками одаренности могут быть решены за счет отбора и систематизации технологий, методов, приемов и средств сопровождения; разработки адекватных целям сопровождения технологий сопровождения.

Пятое направление аспектного анализа («управление процессом сопровождения одареннъх детей») связано с изучением условий, обеспечивающих построение процесса сопровождения на основе разработанных моделей, - совокупности 
внешних обстоятельств реализации функций управления и внутренних особенностей деятельности, обеспечивающих сохранение процесса, его целенаправленности и эффективности (Найн, 1999).

На основе анализа организационно-управленческих характеристик моделей психолого-педагогического сопровождения одаренных детей сделаны следующие выводы:

1. Управленческий компонент моделей сопровождения объединяет в себе внешние (содействующие формированию процессуальной составляющей системы сопровождения) и внутренние (обеспечивающие воздействие на одаренных детей, их педагогов и родителей) воздействия.

2. В разработках моделей сопровождения одаренных детей выделены нормативноправовые, содержательные, организационные, материально-технические, кадровые, научнометодические условия моделируемого процесса. Авторы многих моделей предлагают не отдельные условия, а их комплексы (взаимосвязанные между собой и взаимозависимые организационные/организационно-педагогические/педагогические условия).

3. Авторы моделей приводят критерии оценки эффективности (результативности) психолого-педагогического сопровождения одаренных детей: определяющие достижение цели, выполнения задач, результативности деятельности по каждому направлению сопровождения, качества психолого-педагогического процесса, качества образовательного процесса и др.

4. Среди существенных недостатков организационно-управленческого компонента моделей процесса сопровождения одаренных детей выделим следующие: не сформулированы (или не приводятся) параметры для оценки результативности сопровождения; отсутствует элемент, предусматривающий институциональное (межведомственное) взаимодействие образовательных и иных организаций, других структур в системе сопровождения; не приводятся механизмы создания структуры, координирующей деятельность специалистов сопровождения.

Ключевъци проблемами в разработке организационно-управленческой структуры психолого-педагогического сопровождения одаренных детей являются: 1) проблема обеспечения взаимодействия субъектов образовательного пространства образовательной организации, решение которой обеспечит координацию их деятельности, интеграцию усилий, системность в работе с одаренными детьми, интеграцию ресурсов и оптимизацию процесса управления; 2) проблема создания системы ресурсного (нормативно-правового, информационного, научно-методического, материальнотехнического) обеспечения процесса сопровождения одаренных детей в образовательной организации; 3) проблема разработки механизмов взаимодействия и взаимосвязи организаций дополнительного и общего образования и представляющих их специалистов, решение которой может обеспечить непрерывность сопровождения одаренного ребенка в социуме.

Для решения этих проблем необходимо определить возможности использования культурно-образовательной среды, функции и роли субъектов процесса сопровождения, построить систему институционального (или межведомственного) взаимодействия, спланировать взаимодействие педагога-психолога, педагогов и других специалистов.

\section{5. Заключение}

Изученные модели процесса психолого-педагогического сопровождения одаренных детей имеют схожие (инвариантные) и отличающиеся (вариативные) части, что обусловлено не только объектами сопровождения, спецификой условий, в которых оно осуществляется, но и выбранными авторами моделей методологическими основами организации психологопедагогической работы.

В теоретических моделях изучаемого процесса выделены четыре уровня: теоретический (выбор авторами моделей теоретической основы сопровождения одаренных детей и развития детской одаренности), организационный (поэтапная организация работы специалистов службы сопровождения), технологический (технологии сопровождения), управленческий.

Большинство проанализированных моделей не лишены серьезных изъянов, что объясняется, с одной стороны, сложностью самого моделируемого процесса, а с другой - 
ошибками авторов моделей в педагогическом проектировании, их недостаточной теоретической подготовкой к моделированию работы с одаренными детьми, ограниченным арсеналом освоенных профессиональных средств работы с одаренными детьми, ошибочными представлениями о результатах, содержании, обусловленности результатов процесса сопровождения одаренных детей различными средствами.

Проведенный анализ теоретических моделей процесса психолого-педагогического сопровождения одаренных детей позволит осуществить моделирование этого процесса на более качественном уровне.

\section{Литература}

Богоявленская и др., 2003 - Богоявленская Д.Б. и др. Рабочая концепция одаренности. М.: Министерство образования Российской Федерации. Федеральная целевая программа «Одаренные дети», 2003. 95 с.

Жалагина и др., 2014 - Жалагина Т.A. Структурно-организационные условия психолого-педагогического сопровождения одаренных детей // Психология профессионала: личность, деятельность, организация / под ред. Т.А. Жалагиной, Л.Ж. Каравановой, Е.Д. Короткиной. Тверь: Тверской гос. ун-т, 2014. С. 92-109.

Казакова, 1998 - Казакова E.A. Четыре тенденции и другие проблемы сопровождения // Школьный психолог. 1998. № 48.

Казакова, 2001 - Казакова Е.И. Сопровождение развития - новая образовательная технология // Психолого-педагогическое медико-социальное сопровождение развития ребенка. СПб., 2001. С. 9-14.

Кошелева, 2013 - Кошелева Л.А. Модели сопровождения одаренного ребенка в условиях образовательного учреждения: учеб.-метод. комплект. Барнаул: АКИПКРО, 2013. $52 \mathrm{c}$.

Мельникова и др., 2015 - Мельникова О.В., Красавина Л.В., Птачек Е.В. Модель организационно-педагогического выявления и сопровождения интеллектуально одаренных детей в условиях дополнительного образования // Образование и наука в современных условиях: матер. V Междунар. науч.-практ. конф. (Чебоксары, 9 окт. 2015 г.) / редкол.: О.Н. Широков и др. Чебоксары: ЦНС «Интерактив плюс», 2015. № 4 (5). С. 98-102.

Методические рекомендации... - Методические рекомендации по психологопедагогическому сопровождению обучающихся в учебно-воспитательном процессе в условиях модернизации образования [Электронный ресурc]. URL: http://portal.loiro.ru/files/users127opsihologop.doc

Михеев, 1987 - Михеев В.И. Моделирование и методы теории измерений в педагогике. М.: Высш. школа, 1987. 200 с.

Найн, 1999 - Найн А.Я. Общенаучные понятия в педагогике // Педагогика. 1999. № 78. C. $15^{-19}$.

Новиков, Новиков, 2004 - Новиков А.М., Новиков Д.А. Образовательный проект: методология образовательной деятельности. М.: Эгвес, 2004. 120 с.

Паненкова, 2014 - Паненкова Ю.В. Прикладные аспекты психолого-педагогического сопровождения адаптации одаренных детей в условиях начальной школы // Вестник МГОУ. Серия «Психологические науки». 2014. № 1. С. 73-82.

Толстопятова, 2004 - Толстопятова O.A. Психолого-педагогическое сопровождение обучения и развития интеллектуально-одаренных детей в условиях организации дополнительного общего образования: дис. ... канд. пед. наук. Ставрополь, 2004. 171 с.

Тюнников, 2012а - Тюнников Ю.С. Критериальное ядро сценарного подхода к построению образовательных программ ДПО // Известия Сочинского государственного университета. 2012. № 1 (23). С. 121-131.

Тюнников, 2012b - Тюнников Ю.С. Сценарное моделирование программы дополнительного профессионального образования // Известия Сочинского государственного университета. 2012. № 3 (21). С. 166-173.

\section{References}

Bogoyavlenskaya i dr., 2003 - Bogoyavlenskaya D.B. i dr. (2003). Rabochaya kontseptsiya odarennosti [Working concept of giftedness]. M.: Ministerstvo obrazovaniya Rossiiskoi Federatsii. 
Federal'naya tselevaya programma «Odarennye deti», $95 \mathrm{~s}$.

Kazakova, 1998 - Kazakova E.A. (1998). Chetyre tendentsii i drugie problemy soprovozhdeniya [Four Trends and Other Support Problems]. Shkol'nyi psikholog. № 48.

Kazakova, 2001 - Kazakova E.I. (2001). Soprovozhdenie razvitiya - novaya obrazovatel'naya tekhnologiya [Maintenance of development - a new educational technology]. Psikhologopedagogicheskoe mediko-sotsial'noe soprovozhdenie razvitiya rebenka. SPb., S. 9-14.

Kosheleva, 2013 - Kosheleva L.A. (2013). Modeli soprovozhdeniya odarennogo rebenka v usloviyakh obrazovatel'nogo uchrezhdeniya: ucheb.-metod. komplekt [Models of accompanying a gifted child in the conditions of an educational institution: the teaching method]. Barnaul: AKIPKRO, $52 \mathrm{~s}$.

Mel'nikova i dr., 2015 - Mel'nikova O.V., Krasavina L.V., Ptachek E.V. (2015). Model' organizatsionno-pedagogicheskogo vyyavleniya i soprovozhdeniya intellektual'no odarennykh detei $\mathrm{v}$ usloviyakh dopolnitel'nogo obrazovaniya [Model of organizational and pedagogical identification and support of intellectually gifted children in conditions of additional education]. Obrazovanie $\mathrm{i}$ nauka v sovremennykh usloviyakh: mater. V Mezhdunar. nauch.-prakt. konf. (Cheboksary, 9 okt. 2015 g.). Redkol.: O.N. Shirokov i dr. Cheboksary: TsNS «Interaktiv plyus», № 4 (5). S. 98-102.

Metodicheskie rekomendatsii.. - Metodicheskie rekomendatsii po psikhologopedagogicheskomu soprovozhdeniyu obuchayushchikhsya $\mathrm{v}$ uchebno-vospitatel'nom protsesse $\mathrm{v}$ usloviyakh modernizatsii obrazovaniya [Methodological recommendations on psychological and pedagogical support of students in the teaching and educational process in terms of educational modernization]. [Elektronnyi resurs]. URL: http://portal.loiro.ru/files/users127opsihologop.doc

Mikheev, 1987 - Mikheev V.I. (1987). Modelirovanie i metody teorii izmerenii v pedagogike [Modeling and methods of measurement theory in pedagogy]. M.: Vyssh. shkola, $200 \mathrm{~s}$.

Nain, 1999 - Nain A.Ya. (1999). Obshchenauchnye ponyatiya v pedagogike [General scientific concepts in pedagogy]. Pedagogika. № 7-8. S. 15-19.

Novikov, Novikov, 2004 - Novikov A.M., Novikov D.A. (2004). Obrazovatel'nyi proekt: metodologiya obrazovatel'noi deyatel'nosti [Educational project: methodology of educational activities]. M.: Egves, $120 \mathrm{s.}$

Panenkova, 2014 - Panenkova Yu.V. (2014). Prikladnye aspekty psikhologopedagogicheskogo soprovozhdeniya adaptatsii odarennykh detei $\mathrm{v}$ usloviyakh nachal'noi shkoly [Applied aspects of psychological and pedagogical support for the adaptation of gifted children in primary school terms]. Vestnik MGOU. Seriya «Psikhologicheskie nauki». № 1. S. 73-82.

Tolstopyatova, 2004 - Tolstopyatova O.A. (2004). Psikhologo-pedagogicheskoe soprovozhdenie obucheniya i razvitiya intellektual'no-odarennykh detei v usloviyakh organizatsii dopolnitel'nogo obshchego obrazovaniya [Psychological and pedagogical support of training and development of intellectually gifted children in terms of organization of additional general education]: dis. ... kand. ped. nauk. Stavropol', $171 \mathrm{s.}$

Tyunnikov, 2012a - Tyunnikov Yu.S. (2012). Kriterial'noe yadro stsenarnogo podkhoda k postroeniyu obrazovatel'nykh programm DPO [The critical core of the scenario approach to the construction of educational programs APE]. Izvestiya Sochinskogo gosudarstvennogo universiteta. № 1 (23). S. 121-131.

Tyunnikov, 2012b - Tyunnikov Yu.S. (2012). Stsenarnoe modelirovanie programmy dopolnitel'nogo professional'nogo obrazovaniya [Scenario modeling of the program of additional professional education]. Izvestiya Sochinskogo gosudarstvennogo universiteta. № 3 (21). S. 166-173.

Zhalagina i dr., 2014 - Zhalagina T.A. (2014). Strukturno-organizatsionnye usloviya psikhologo-pedagogicheskogo soprovozhdeniya odarennykh detei [Structural and organizational conditions of psychological and pedagogical support of gifted children]. Psikhologiya professionala: lichnost', deyatel'nost', organizatsiya. Pod red. T.A. Zhalaginoi, L.Zh. Karavanovoi, E.D. Korotkinoi. Tver': Tverskoi gos. un-t, S. 92-109. 
УДК 37

\section{Современные модели психолого-педагогического сопровождения одаренных детей}

Наталия Ивановна Нескоромных ${ }^{\text {a }}$ *

${ }^{\text {a } е н н т р ~ т в о р ч е с к о г о ~ р а з в и т и я ~ и ~ г у м а н и т а р н о г о ~ о б р а з о в а н и я ~ г . ~ С о ч и, ~ Р о с с и и ̆ с к а я ~ Ф е д е р а ц и я ~}$

Аннотация. В статье представлены результаты исследования вопросов моделирования и проектирования профессиональной деятельности по сопровождению одаренных детей. Материалом для анализа стали научные работы, в которых описаны как результаты моделирования функционирующих психолого-педагогических объектов, так и не существующие (предлагаемые) модели процесса психолого-педагогического сопровождения одаренных детей. На основе системного анализа и сравнительного подхода рассмотрены состав, структура (методологический, целевой, содержательный, структурный, технологический, управленческий компоненты), иерархия компонентов моделей, а также выделены ключевые проблемы проектирования каждого из них. Показано, что психологопедагогическое сопровождение одаренных детей в образовательных организациях, построенное на основе теоретических моделей, не лишено серьезных недостатков. Предложены пути преодоления выявленных погрешностей моделей.

Проведенный анализ теоретических моделей процесса психолого-педагогического сопровождения одаренных детей позволит осуществить моделирование этого процесса на более качественном уровне и избежать существенных ошибок в моделировании.

ключевые слова: одаренные дети, психолого-педагогическое сопровождение одаренных детей, моделирование, модель психолого-педагогического сопровождения одаренных детей.

${ }^{*}$ Корреспондирующий автор

Адрес электронной почты: nesknatali@mail.ru (Н.И. Нескоромных) 